\title{
Improvement in bronchial hyper-responsiveness in patients with moderate asthma after treatment with a hypnotic technique: a randomised controlled trial
}

\author{
TIMOTHY C EWER, DONALD E STEWART
}

\begin{abstract}
A prospective, randomised, single blind, and controlled trial of a hypnotic technique was undertaken in 39 adults with mild to moderate asthma gradad for low and high susceptibility to hypnosis. After a six week course of hypnotherapy 12 patients with a high susceptibility score showed a $74.9 \%$ improvement $(\mathbf{p}<0.01)$ in the degree of bronchial hyper-responsiveness to a standardised methacholine challenge test. Daily home recordings of symptoms improved by $41 \%(p<0.01)$, peak expiratory flow rates improved by $5.5 \%(p<0.01)$, and use of bronchodilators decreased by $26.2 \%(p<0.05)$. The improvement in bronchial hyper-reactivity occurred without a change in subjective appreciation of the degree of bronchoconstriction. A control group 17 patients and 10 patients undergoing treatment with low susceptibility to hypnosis had no change in either bronchial hyper-responsiveness or any of the symptoms recorded at home.

This study shows the efficacy of a hypnotic technique in adult asthmatics who are moderately to highly susceptible to hypnosis.
\end{abstract}

\section{Introduction}

Although orthodox medical practice offers numerous effective treatments, patients with asthma continue to seek relief from a variety of alternative regimens, which have achieved widespread acceptability despite the lack of conventional proof of efficacy.'

Several psychosomatic studies have suggested that hypnosis or relaxation, or both, may be useful in the treatment of asthma. ${ }^{2-16}$ The reported success of these studies is questionable owing to the lack of matched control groups and appropriate physiological and

Departments of Respiratory Medicine and Psychological Medicine, Princess Margaret Hospital, Christchurch, New Zealand

TIMOTHY C EWER, MRCP, FRACP, consultant physician

DONALD E STEWART, MB, FRACP, lecturer in respiratory medicine

Correspondence to: Dr T C Ewer, Princess Margaret Hospital, Private Bag, Christchurch, New Zealand. psychological measurements. No study has investigated whether any apparent improvement is a result of a decrease in bronchial responsiveness or simply a decrease in awareness of the degree of bronchoconstriction. The latter possibility could endanger life if it resulted in delay or failure to seek effective treatment in an attack of asthma.

We report a prospective, randomised, and controlled investigation into the efficacy of a hypnotic technique in a group of adults with mild to moderate asthma assessed by a standardised methacholine inhalation challenge test.

\section{Patients and methods}

Forty four patients with a history of mild to moderate asthma were recruited from the local community. Patients were aged between 18 and 45 years and all gave a history of episodic wheeze or shortness of breath, or both. Each patient was told that the aim of the trial was to assess the possible benefit of a "relaxation technique" to control symptoms of asthma. The study was approved by the hospital ethical committee and the patients provided written informed consent.

The exclusion criteria were: a reduction of less than $20 \%$ in the ratio of forced expiratory volume in one second to forced vital capacity with the maximum concentration of metacholine; a history of severe asthma (prior admission to hospital which had required ventilatory support or admission with an arterial carbon dioxide pressure of more than $5.33 \mathrm{kPa}(40 \mathrm{mmHg})$ ); concurrent systemic steroid treatment; pregnancy; and a history of psychosis or relevant medical illness, including a history of bronchitis that fulfilled the standard criteria. ${ }^{17}$

The patients were divided into two groups according to whether they showed low (score $0-2$ ) or high (score 3-5) susceptibility to hypnosis on the Stanford hypnotic clinical scale. ${ }^{18}$ This is a short, clinically oriented test, which is easy to perform and consists of a progressive relaxation induction followed by the suggestions of moving hands together, a dream, age regression, a posthypnotic suggestion, and amnesia. It correlates well with the longer and standardised Stanford hypnotic susceptibility scales and the Harvard group scale of hypnotic susceptibility. ${ }^{19}$

The senior outpatient nursing sister (who was not otherwise concerned with the trial) then randomised the patients of both groups independently into treatment and control groups.

All subjects completed a diary, which consisted of the following: peak expiratory flow rates measured twice daily using a Wright peak flow meter, daily use of drugs, and graded scores of five symptoms related to asthma (cough, activity limitation, wheeze, phlegm, and nocturnal symptoms). 
Treatment consisted of six weekly, half hour sessions of a hypnotic technique undertaken by one of us (TE) as described below. Patients in the control group were seen at weekly intervals for six weeks by the nurse in the asthma clinic, who reviewed the diary recordings of each patient. No attempts were made to adjust medication or influence any aspect of current treatment.

Challenges with methacholine were undertaken without knowing which group the patient was in and the tests before and after treatment were performed at the same time of day and with the patient abstaining from bronchodilator treatment for at least 12 hours before testing. Both the methacholine challenge test and the psychological assessment were carried out before and one week after the trial period.

The forced vital capacity, forced expiratory volume in one second, ratio of forced vital capacity to forced expiratory volume in one second, peak expiratory flow rate, and maximum expiratory flow at $50 \%$ vital capacity were measured by computerised flow volume spirometry logged on a PDP $11 / 10$ computer. Static lung volumes and airways resistance were estimated using a Collins plethysmograph.

The challenge technique used an ultrasonically nebulised mist generated by the constant infusion of a methacholine solution of known concentration on to the surface of a piezoelectric crystal within an enclosed chamber, which was constantly flushed by air at a flow rate of $25 \mathrm{l} / \mathrm{min} .{ }^{20} \mathrm{After}$ the patient had exhaled to residual volume he was switched into the exhaust tubing of the nebulised chamber. He then inhaled slowly to total lung capacity and held his breath for three seconds. The minimum concentration of mist was $2.9 \mu \mathrm{g}$ of methacholine per litre, with the concentration doubling at each successive challenge. The minimum criterion for bronchial hyper-responsiveness was a $20 \%$ decrease in the forced expiratory volume in one second at or before the maximum concentration of $384 \mu \mathrm{g} / 1$

A minimum of two forced expiratory manoeuvres were performed two minutes after completing the inhalation test. The challenge test was stopped if the ratio of forced expiratory volume in one second to forced vital capacity fell to less than $80 \%$ of the value before the test. For each challenge test the patient was asked to score the degree of chest tightness between zero (no symptoms) and 10 (worst possible symptoms).

The hypnotic technique started with an introductory discussion, which combined an outline of the treatment procedures, a general description of hypnosis, and a hypnotic induction. This was followed by suggestions of progressive relaxation, ego enhancement, and a method of self hypnosis. The remaining five sessions began with a similar but shortened induction, followed by a progression of guided imageries. By the final two sessions symptoms of asthma could be rapidly produced and immediately resolved under the subject's own control. Psychological profiles included the statetrait anxiety inventory, ${ }^{21}$ Zung's self rating depression scale, ${ }^{22}$ and Pilowsky's illness behaviour questionnaire. ${ }^{23}$

\section{ANALYSIS}

Daily symptom scores, peak flow recordings, and drug use were averaged for the first two weeks and the last two weeks of the treatment period. Bronchial hyper-responsiveness to methacholine was calculated as the intercept of the computer fitted least squares line of forced expiratory volume in one second versus dosage at which the forced expiratory volume in one second was reduced to $80 \%$ of the initial value. Subjective sensitivity was the slope of the least squares line for subjective score versus forced expiratory volume in one second and was expressed as change in forced expiratory volume in one second per unit change in score. Where variances of groups did not differ significantly Student's $t$ test was used, and where significant variances did occur Brown Forsyth adjustments were made..$^{2+}$

\section{Results}

Thirty nine of the 44 patients recruited completed the trial $(24$ women and 15 men). Five control patients failed to complete the trial: two moved from the area, and three others declined to complete the repeat testing. Thirty nine patients completed the two bronchial challenge tests but four did not complete the home recording diary. There were no significant differences between the two groups with respect to age, sex, atopy, duration of asthma, drug treatment, or baseline respiratory function tests (table I).

Table II compares results of lung function tests in the control and treatment groups before and after treatment. Thee were no significant differences between the two groups in expiratory flow measurements, static lung volumes, or airways resistance before treatment. After treatment there was a small but significant improvement in the forced vital capacity in both the control and treatment groups of $5.03 \%$ and $6.9 \%$ respectively. In addition, the treatment group showed a significant improvement in both the peak expiratory flow rate and the maximum expiratory flow rate at $50 \%$ vital capacity after treatment of $11.7 \%$ and $14.7 \%$ respectively.
The patients with high susceptibility to hypnosis who underwent the $\underline{\underline{W}}$ hypnotic technique showed a $74.9 \%(\mathrm{p}<0.01)$ improvement in bronchial 3 hyper-responsiveness (table III). Neither the low susceptibility treatment $\stackrel{\mathbb{Q}}{\stackrel{\mathbb{Q}}{2}}$ group nor the control group showed any improvement.

The subjective score during the methacholine challenge test correlated with the forced expiratory volume in one second $(r=0.905, p<0.002)$, with an overall mean (SD) change in forced expiratory volume in one second of

TABLE I -Details of patients in the control and treatment groups

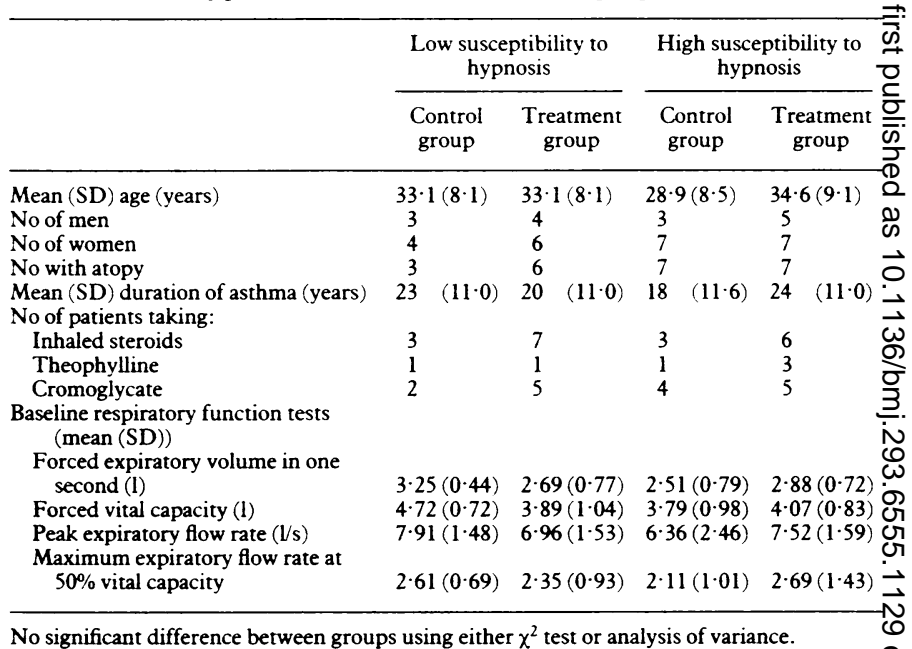

No significant difference between groups using either $\chi^{2}$ test or analysis of variance.

TABLE II-Results of lung function tests before and after treatment. Values are meanso (SEM)

\begin{tabular}{|c|c|c|c|}
\hline & & Control group & Treatment groups \\
\hline Forced vital capacity (1) & $\left\{\begin{array}{l}\text { Before } \\
\text { After }\end{array}\right.$ & $\begin{array}{l}4 \cdot 04(0 \cdot 22) \\
4 \cdot 27(0 \cdot 20)^{\star}\end{array}$ & $\begin{array}{l}4.18(0.18) \\
4.47(0.17)+\end{array}$ \\
\hline $\begin{array}{l}\text { Forced expiratory volume in } \\
\text { one second (1) }\end{array}$ & $\left\{\begin{array}{l}\text { Before } \\
\text { After }\end{array}\right.$ & $\begin{array}{l}2 \cdot 79(0 \cdot 19) \\
2 \cdot 92(0 \cdot 17)\end{array}$ & $\begin{array}{l}2 \cdot 83(0 \cdot 20) \\
3 \cdot 07(0 \cdot 13)\end{array}$ \\
\hline $\begin{array}{l}\text { Ratio of forced expiratory volume in } \\
\text { one second to vital capacity }(\%)\end{array}$ & $\left\{\begin{array}{l}\text { Before } \\
\text { After }\end{array}\right.$ & $\begin{array}{l}70 \cdot 9(2 \cdot 66) \\
69 \cdot 4(2 \cdot 39)\end{array}$ & $\begin{array}{l}67 \cdot 3(2 \cdot 48) \\
70 \cdot 2(2 \cdot 07)\end{array}$ \\
\hline Peak expiratory flow rate $(\mathrm{l} / \mathrm{s})$ & $\left\{\begin{array}{l}\text { Before } \\
\text { After }\end{array}\right.$ & $\begin{array}{l}7 \cdot 13(0 \cdot 46) \\
7 \cdot 67(0 \cdot 42)\end{array}$ & $\begin{array}{l}7.41(0.39) \\
8.32(0.40) \dagger\end{array}$ \\
\hline $\begin{array}{l}\text { Maximum expiratory flow rate at } \\
50 \% \text { vital capacity }(\mathrm{l} / \mathrm{s})\end{array}$ & $\left\{\begin{array}{l}\text { Before } \\
\text { After }\end{array}\right.$ & $\begin{array}{l}2 \cdot 17(0 \cdot 19) \\
2 \cdot 12(0 \cdot 21)\end{array}$ & $\begin{array}{l}1 \cdot 98(0 \cdot 22) \\
2 \cdot 27(0 \cdot 20)^{\star}\end{array}$ \\
\hline Functional residual capacity (1) & $\left\{\begin{array}{l}\text { Before } \\
\text { After }\end{array}\right.$ & $\begin{array}{l}3.61(0 \cdot 24) \\
3 \cdot 39(0 \cdot 17)\end{array}$ & $\begin{array}{l}3.75(0.39) \\
3.45(0.18)\end{array}$ \\
\hline Residual volume (I) & $\left\{\begin{array}{l}\text { Before } \\
\text { After }\end{array}\right.$ & $\begin{array}{l}2 \cdot 31(0 \cdot 22) \\
2 \cdot 01(0 \cdot 16)\end{array}$ & $\begin{array}{l}2 \cdot 54(0 \cdot 36) \\
2 \cdot 23(0 \cdot 16)\end{array}$ \\
\hline Airways resistance $\left(\mathrm{cm} \mathrm{H}_{2} \mathrm{O} / \mathrm{s}\right)$ & $\left\{\begin{array}{l}\text { Before } \\
\text { After }\end{array}\right.$ & $\begin{array}{l}2 \cdot 48(0 \cdot 22) \\
2 \cdot 34(0 \cdot 21)\end{array}$ & $\begin{array}{l}2 \cdot 21(0 \cdot 20) \\
2 \cdot 13(0 \cdot 13)\end{array}$ \\
\hline
\end{tabular}

${ }^{\star} \mathrm{p}<0.05, \mathrm{fp}<0.002$ (paired $t$ test, difference between values before and after treatment).

TABLE III-Bronchial responsiveness and patients' subjective sensitivity to changes in forced expiratory volume in one second during methacholine challenge before and after treatment

\begin{tabular}{|c|c|c|c|c|c|}
\hline & \multicolumn{2}{|c|}{$\begin{array}{c}\text { Low susceptibility to } \\
\text { hypnosis }\end{array}$} & \multicolumn{2}{|c|}{$\begin{array}{l}\text { High susceptibility to } \\
\text { hypnosis }\end{array}$} & 高 \\
\hline & $\begin{array}{l}\text { Control } \\
\text { group }\end{array}$ & $\begin{array}{l}\text { Treatment } \\
\text { group }\end{array}$ & $\begin{array}{l}\text { Control } \\
\text { group }\end{array}$ & $\begin{array}{l}\text { Treatment } \\
\text { group }\end{array}$ & స్ట \\
\hline \multirow{2}{*}{\multicolumn{5}{|c|}{$\begin{array}{l}\text { Bronchial responsiveness } \\
\left.\text { (mean } \mathrm{PC}_{20}(\mathrm{SEM})\right)\end{array}$}} & \\
\hline Before treatment & & & & & \\
\hline After treatment & $14 \cdot 7(3.08)$ & $9 \cdot 8(1 \cdot 12)$ & $8 \cdot 2(1 \cdot 00)$ & $15.9(2.79)$ & \\
\hline$\%$ Change & -31 & -25 & -30 & +75 & \\
\hline p† & $0 \cdot 14$ & $0 \cdot 12$ & $0 \cdot 10$ & 0.008 & ס \\
\hline \multicolumn{5}{|l|}{$\begin{array}{l}\text { Subjective sensitivity } \\
(\text { ml unit score }(\text { SEM }))\end{array}$} & \\
\hline Before & $278(32)$ & $277(29)$ & $257(33)$ & $272(30)$ & 5 \\
\hline After & $303(32)$ & $327(34)$ & $308(24)$ & $262(34)$ & \\
\hline p† & 0.70 & 0.008 & 0.029 & 0.77 & \\
\hline
\end{tabular}

^For details see Methods section.

+Statistical significance of difference between values before and after treatment using paired $t$ 응

$\mathrm{PC}_{20}=$ Provocation concentration of methacholine that caused a $20 \%$ fall in forced expiratory volume in one second. 
271 (76) $\mathrm{ml}$ per unit change in subjective score. Patients with low susceptibility to hypnosis who received treatment and those with high susceptibility who acted as controls has significant decreases in the degree of subjective sensitivity during the methacholine challenge test of $18 \%$ and $20 \%$ respectively (table III), whereas the high susceptibility treatment group showed no change.

TABLE IV-Home diary recordings: peak expiratory flow rate, use of sympathomimetic bronchodilator drugs, and percentage change in symptom scores before and after treatment. Values are means (SEM)

\begin{tabular}{|c|c|c|c|c|}
\hline & \multicolumn{2}{|c|}{$\begin{array}{c}\text { Low susceptibility to } \\
\text { hypnosis }\end{array}$} & \multicolumn{2}{|c|}{$\begin{array}{l}\text { High susceptibility to } \\
\text { hypnosis }\end{array}$} \\
\hline & $\begin{array}{l}\text { Control } \\
\text { group }\end{array}$ & $\begin{array}{l}\text { Treatment } \\
\text { group }\end{array}$ & $\begin{array}{l}\text { Control } \\
\text { group }\end{array}$ & $\begin{array}{l}\text { Tretment } \\
\text { group }\end{array}$ \\
\hline \multicolumn{5}{|c|}{ Peak expiratory flow rate ( $\mathrm{l} \mathrm{min})$} \\
\hline Before & $434(42)$ & $388(39)$ & $380(30)$ & $371(30)$ \\
\hline After & $432(42)$ & $389(41)$ & $380(29)$ & $406(30) \dagger$ \\
\hline \multicolumn{5}{|c|}{ Use of bronchodilator drugs (puffs day) } \\
\hline Before & $23 \cdot 5(7 \cdot 5)$ & $49 \cdot 1(11 \cdot 4)$ & $38 \cdot 7(13 \cdot 8)$ & $46 \cdot 0(7 \cdot 2)$ \\
\hline \multirow{2}{*}{\multicolumn{5}{|c|}{ Percentage change in symptom scores }} \\
\hline & & & & \\
\hline Sleep & -59 & -12 & -22 & $-62^{\star}$ \\
\hline Wheeze & -25 & -10 & -20 & $-53 \ddagger$ \\
\hline Activity & +143 & -34 & +11 & $-58 t$ \\
\hline Cough & +23 & -25 & -28 & -23 \\
\hline Phlegm & -33 & -44 & +8 & -20 \\
\hline
\end{tabular}

Statistical significance between values before and after treatment using paired $t$ test: ${ }^{\star} p<0.05$; $\dagger \mathrm{p}<0.01 ; \neq \mathrm{p}<0 \cdot 001$

In the high susceptibility group the subjective scores for nocturnal symptoms, wheeze, and activity limitation and peak flow rates improved after treatment by $62 \%(\mathrm{p}<0.05), 53 \%(\mathrm{p}<0.01), 40 \%(\mathrm{p}<0.01)$, and $5.5 \%$ $(p<0.01)$ respectively. No significant change was found in either the low susceptibility treatment group or in the control group (table IV). There was no change in the scores for cough and sputum production in any group. The use of inhaled bronchodilator drugs decreased from a mean of 4.6 puffs a day to 3.4 puffs a day $(\mathrm{p}<0.05)$ in the high susceptibility treatment group but not in any of the other groups (table IV.)

\section{Discussion}

Despite the accepted importance of the psyche in asthma, scientific endeavour has been largely directed towards pharmacological techniques for treating asthma. The relatively few studies that have used hypnotic techniques have failed to provide adequare evidence for a significant therapeutic effect because of poor methods. In 1959 Diamond reported a 73\% "complete remission of symptoms" without any objective documentation. ${ }^{3}$ MaherLoughnan et al reported that $59 \%$ of 127 patients were "much improved,"s and in another, uncontrolled study $82 \%$ of 173 patients had a "convincing response to treatment." 10 Both relied on symptom scores without objective evaluation of respiratory function. In an uncontrolled and retrospective study Collison ${ }^{8}$ reported that $21 \%$ of his treated patients were "drug free," and 33\% had a "worthwhile decrease in frequency or severity of symptoms," but he also failed to measure respiratory function objectively.

Our study showed that a hypnotic technique had a significantly beneficial effect on bronchial hyper-responsiveness as measured by a methacholine inhalation challenge test. The improvement in patients' symptoms together with improvement in the peak expiratory flow rates and decreased use of inhaled sympathomimetic drugs indicate that the $74.9 \%$ improvement in bronchial hyperresponsiveness sensitivity is clinically important. That these improvements were confined to the group of patients with a high level of susceptibility to hypnosis who were receiving treatment and were not seen in the control group or those patients treated by hypnosis but who had a low susceptibility to it is entirely consistent with the suggestion that the benefit was due to the hypnotic technique alone rather than a non-specific effect. The pattern of response also suggests that the high and low susceptibility groups in this study may be the same as the "reactors" and "non-reactors" to suggestion that were identified in a group of patients with mild asthma by Strupp et al. ${ }^{2 s}$

Clinical trials of psychosomatic treatments, where the use of truly blinded treatment is impossible, require careful elimination of bias in the recruitment, randomisation, and assessment methods. The use of four independent agencies for the various aspects of the trial (independent randomisation, separate control and treatment therapists, and blinded laboratory testing) is the best way to avoid the subtle selection processes that can invalidate conclusions. Analysis of susceptibility to hypnosis and psychological profiles, the details of which are to be reported elsewhere, showed no difference between the control and treatment groups and that the data were consistent with known population profiles. ${ }^{26}$

Although hypnotherapy is unlikely to have adverse effects, successful treatment might alter the patient's appreciation of the severity of the airways obstruction, leading to a delay in seeking appropriate emergency treatment. In the treatment group we took care to minimise this possibility by suggestions given during hypnosis of increased awareness of symptoms of asthma, attention to the need for appropriate action, and the avoidance of symptom denial. The highly susceptible patients showed no significant change in subjective sensitivity after treatment. Although subjective appreciation of bronchoconstriction during a methacholine challenge test cannot be equated with conditions in everyday life, our results indicate the relative safety of this hypnotic technique.

The mechanism of the psychosomatic response in asthma has not been established, nor has the cause of asthma itself. Philipp et al ${ }^{12}$ proposed a model in which a shift in autonomic arousal induces a change in bronchial sensitivity to local stimuli such as inhaled allergens or non-specific irritants. In an asthma attack "self perception" of the bronchoconstriction will induce anxiety, which, if not accommodated successfully, will increase autonomic arousal and produce a positive feedback stimulus exacerbating the bronchoconstrictor response. Psychosomatic methods may act by directly decreasing the level of autonomic arousal, deconditioning the primary central stimulus, or inhibiting the positive "self perception" feedback loop. ${ }^{27}$

There are several studies in animals and man which collectively provide strong indirect evidence of a cholinergic vagal pathway by which psychogenic stimuli may affect bronchial hypersensitivity. Suggestion appears to affect the larger airways, ${ }^{28}$ which is consistent with the known distribution of the vagus within the bronchial tree. ${ }^{29}$ Direct stimulation of the vagus induces a heightened response to histamine challenge, ${ }^{30}$ while in the guinea pig atropine blocks the classic Pavlovian conditioned bronchospasm, but not that induced by allergens. ${ }^{31}$ Atropine $^{32}$ and ipratropium ${ }^{33}$ both decrease the bronchospasm induced by suggestion in patients with mild asthma. This model of psychogenic interaction with bronchial hyperresponsiveness is also consistent with the observation that atropine blocks morphine sensitive but not morphine insensitive bronchoconstriction. ${ }^{34}$

Other pathways could be implicated, such as the recently described non-adrenergic, non-cholinergic bronchodilator system, ${ }^{35}$ but clear evidence will depend on the development of a specific neural blocker.

While our hypnotic technique does not eliminate bronchial hyper-responsiveness it does provide a clinically useful and nontoxic adjuvant to drug treatment that might benefit about half of the asthmatic population. In subjective terms the perception of control over the degree of bronchospasm, accompanied by diminished anxiety, often results in an enhanced feeling of health and confidence. Many patients reported that this sense of wellbeing paralleled improvements in other aspects of their lives such as general stress management, insomnia, and other psychosomatic symptoms.

We thank Tom Tanner, Maureen Graves, and Michael Won for their technical help; Michael Won and Dr Elizabeth Wells for their help in the statistical analysis; Dr Mike Davis for his useful comments; Mrs L Lowe and Mrs G Naisbit, of the outpatient nursing staff, who arranged outpatient reviews; and John Bushnell and Dr J Walshe, who advised on the hypnotic technique and psychological tests. 


\section{References}

1 Smith T. Alternative medicine. Br Med f 1983;287:307.

2 Herxheimer H, Prior FN. Further observations on induced asthma and bronchial hyposensitization. Inl Arch Allergy Appl Immunol 1952;3:189-207.

3 Diamond HH. Hypnosis in children: complete cure of 40 cases of asthma. American foumal of Hypnosis 1959;1:124-9.

4 Morrison Smith JM, Burns CLC. The treatment of asthmatic children by hypnotic suggestion $B$ 7 Dis Chest 1960;4:78-81.

5 Maher-Loughnan GP, Macdonald N, Mason AA, Fry L. Controlled trial of hypnosis in the svmptomatic treatment of asthma. Br Med 7 1962;ii:371-6.

6 Cooper AJ. A case of bronchial asthma treated by behaviour therapy. Behav Res Ther 1964; $351-6$

7 Moore N. Behaviour therapy in bronchial asthma. A controlled study. I Psychosom Res 1965;9:257-76.

8 Collison DR. Hypnotherapy in the management of asthma. Am 7 Clin Hypn 1968;11:6-11.

9 Sargeant HGS, Yorkston NJ. Verbal desensitisation in the treatment of bronchial asthma. Lance 1969;ii:1329.

10 Maher-Loughnan GP. Hypnosis and autohypnosis for the treatment of asthma. Int $\mathcal{f}$ Clin Exp Hypn 1970;18:1-14.

11 Alexander $\mathrm{AB}$, Miklich DR, Hershkoff $\mathrm{H}$. The immediate effects of systematic relaxation training on peak expiratory flow rates in asthmatic children. F Psychosom Res 1972;16:193-204.

2 Philipp RL, Wilde GJS, Day JH. Suggestion and relaxation in asthmatics. 7 Psychosom Res 1972;16:193-204.

13 Aronoff GM, Aronoff S, Peck LW. Hypnotherapy in the treatment of bronchial asthma. Ann Allergy 1975;34:356-62

14 Hock RA, Bramble J, Kennard DW. A comparison between relaxation and assertive training with asthmatic male children. Biol Psychiatry 1977;12:593-6.

15 Alexander $\mathrm{AB}$, Cropp GJA, Chai $\mathrm{H}$. Effects of relaxation on pulmonary mechanics in children with asthma. F Appl Behav Anal 1979;12:27-35.

16 Neinstein LS, Dash J. Hypnosis as an adjunct for asthma. 7 Adolesc Health Care 1982:3:45-8.

17 Meneely GR, Renezetti AD, Steele JD, Wyatt JP, Harris HW. Chronic bronchitis, asthma and pulmonary emphysema. Thorax 1960;15:276-80.

18 Hilgard ER. Hypnosis in the relief of pain. Los Altos: William Kaufmann Inc, 1975.
19 Morgan AH, Hilgard JR. The Stanford hypnotic clinical scale for adults. Am f Clin Hypn $\underset{\underline{T}}{\mathbb{W}}$ 1979;21:134-7. 20 Graves $\mathrm{M}$, Stewart DE. The assessment of bronchial hypersensitivity using a simple ultra-sonic
nebulizer technique. Volume $1985 ; 5: 11$.

21 Spielbeger CD. Manual for the state trait anxiety inventory. Palo Alto: Consulting Psychologist's C Press, 1970.

22 Zung W'WK. A self rating depression scale Arch Gen Psychiatr 1965:12:63-70.

23 Pilowsky I, Spence ND. Abnormal illness behaviour. British fournal of Medical Psychiatry 1969;42:347-52.

24 Dixon WJ, ed. BMDP statistical sofrware. Berkeley: University of California Press, 1981.

25 Strupp HH, Levenson RW, Manuck SB, James JD, Hinrichsen JJ, Boyd S. Effects of suggestion $\&$ on total respiratory resistance in mild asthmatics. $\mathcal{F}$ Psychosom Res 1974;18:337-46.

26 Knight RG, Waal-Manning HJ, Spears GF. Norms of reliability for STAI and ZSDS. Br $\mathcal{J}$ Clin Pharmacol 1983;22:245-9. 27 Erskine-Milliss J, Schonell M. Relaxation therapy in asthma: a critical review. Psychosom Med
1981;43:365-71.

28 Spector S, Luparello TJ, Kopetzky MT, Souhrada J, Kinsman RA. Response of asthmatics to methacholine and suggestion. Am Rev Respir Dis 1976;113:43-50.

29 Richardson JB. Innervation of the lung. Eur $\mathcal{f}$ Respir Dis 1981;117 (suppl ):237-45.

30 Loring SH, Drazen JM, Snapper JR, Ingram RH Jr. Vagal and aerosol histamine interactions on airway response in dogs. 7 Appl Physiol 1978:45:40-4.

31 Justesen DR, Braun EW, Garrison RG, Pendleton RB. Pharmacologic differentiation of allergic and classically conditioned asthma in the guinea pig. Science 1970;170:864-6.

32 McFadden ER Jr. Luparello T, Lyons Ha, Bleeker $\mathrm{F}$. The mechanism of action of suggestion in the induction of acute asthma attacks. Psychosom Med 1969;31:134-43. the induction of acute asthma attacks. Psychosom Med 1969;31:134-43.
33 Rebuck AS, Marcus HI. SCH 1000 in psychogenic asthma. Scandinavian foumal of Respiratory

34 Eschenbacher WL, Bethel RA, Boushey HA, Sheppard D. Morphine sulphate inhibits bronchoconstriction in subjects with mild asthma whose responses are inhibited by atropine. Am Rev Respir Dis 1984;130:363-7.

35 Richardson JB. Non-adrenergic inhibitory innervation of the lung. Lung 1981;159:315-22.

Accepted 14 fuly 1986

\title{
Protracted diarrhoea of infancy: evidence in support of an autoimmune variant
}

\author{
RITA MIRAKIAN, ANNE RICHARDSON, PETER J MILLA, JOHN A WALKER-SMITH, \\ JOSEPH UNSWORTH, MARTIN O SAVAGE, GIAN FRANCO BOTTAZZO
}

\begin{abstract}
Circulating autoantibodies to enterocytes were detected by indirect immunofluorescence in 14 out of 25 patients with idiopathic protracted diarrhoea of infancy. Similar specificities were not found in 50 control children with nongastroenterological disorders. The immunofluorescence pattern was more accentuated on the apical border of mature enterocytes. Enterocyte autoantibodies were mainly of IgG class (13/14), but 11 sera were positive for $\operatorname{IgM}$ and IgA classes, and five out of 14 positive sera also had the ability to fix complement. Absorption of sera positive for autoantibodies with an IgA coupled immunoabsorbent did not modify the intensity of the staining, indicating that these antibodies were not directed against secretory IgA. High titres and the complement fixing ability of enterocyte autoantibodies indicated a poorer prognosis
\end{abstract}

Department of Immunology, Middlesex Hospital Medical School, London W1P 9PG

RITA MIRAKIAN, MD, research associate

ANNE RICHARDSON, BSC, technical assistant

GIAN FRANCO BOTTAZZO, MD, MRCP, reader in clinical immunology, honorary consultant physician

Department of Child Health, Institute of Child Health, London WC1 PETER J MILLA, FRCP, senior lecturer in child health, honorary consultant in paediatric gastroenterology

Department of Paediatric Gastroenterology and Endocrinology, Queen Elizabeth Hospital for Children, London EC2

JOHN A WALKER-SMITH, MD, FRCP, professor of paediatric gastroenterology JOSEPH UNSWORTH, PHD, research assistant

MARTIN O SAVAGE, MD, MRCP, consultant paediatrician

Correspondence to: Dr Bottazzo. despite the use of immunosuppressive drugs. Organ specific and non-organ specific autoimmune diseases or corresponding autoantibodies or both were often found in children with enterocyte $\mathbb{D}$ autoantibodies and their family. These data show the existence $\overrightarrow{\vec{O}}$ of an autoimmune variant of protracted diarrhoea of infancy, despite the rare occurrence of autoimmune diseases in childhood.

\section{Introduction}

Protracted diarrhoea of infancy is due to a heterogeneous group of disorders in which the diagnosis can be identified in about $70 \%$ of the patients. ${ }^{1}$ The remaining unexplained cases almost certainly represent a range of several different conditions and have a high mortality'; the average consultant paediatrician might see one such $\tilde{\sigma}$ patient every year. Isolated cases of idiopathic protracted diarrhoea $>$ of infancy have been described in which circulating autoantibodies to gut enterocytes have been shown by classic indirect immuno- $N$ fluorescence technique..$^{3.7}$ These initial reports suggested that an N autoimmune disorder with characteristics similar to those described $\omega$ in other well recognised organ specific autoimmune diseases might account for some of the hitherto unexplained cases of protracted diarrhoea of infancy. We therefore investigated a larger series of $\stackrel{\mathcal{Q}}{\rightarrow}$ children affected by this condition to define a group of patients in whom this complex syndrome might be related to an autoimmune disorder.

\section{Patients}

Twenty five children ( 15 boys and 10 girls), aged 1 month to 1 year at the onset of symptoms, were investigated for unexplained protracted diarrhoea. 